\title{
Placenta previa and its effect on maternal and fetal outcome: retrospective observational study
}

\section{Durgavathi Kothapalli, Kameswari Kolluru*}

Department of Obstetrics and Gynaecology, Konaseema Institute of Medical Science, Amalapuram, Andhra Pradesh, India

Received: 04 May 2021

Accepted: 29 May 2021

\section{*Correspondence:}

Dr. Kameswari Kolluru,

E-mail: k.kameswari@gmail.com

Copyright: ( $)$ the author(s), publisher and licensee Medip Academy. This is an open-access article distributed under the terms of the Creative Commons Attribution Non-Commercial License, which permits unrestricted non-commercial use, distribution, and reproduction in any medium, provided the original work is properly cited.

\section{ABSTRACT}

Background: Placenta previa is a condition in which placenta get implanted in the lower uterine segment or cervix, which is a major risk factor for postpartum haemorrhage and morbidity and mortality of the mother and neonate used to increase. Based on literature survey we have designed with an objective to study the risk factors for placenta previa and feto-maternal outcome in cases of placenta previa.

Methods: Based on selection criteria 100 singleton deliveries with placenta previa that took place in the department of obstetrics from December 2017 to December 2020 were enrolled and there medical records were considered for analysis. From medical record details of patients like age, duration of gestation, parity, clinical presentation, details of current and previous pregnancy, history of warning bleeding and gestational age of diagnosis of placenta previa.

Results: Regarding risk factor for placenta previa $48 \%$ patients have history of previous LSCS, $22 \%$ patients have history of previous abortions. Regarding anti partum complication bleeding PV was present in $24 \%$ patients, pre-term labour was present in $46 \%$ patients, PIH was present in $10 \%$ patients, and abnormal presentation was present in $14 \%$ patients.

Conclusions: From our study we can conclude that placenta previa is common in multiparous women in third decade of life and commonly detected at 36 weeks. Bleeding per vagina was most common clinical presentation and LCSC is common risk factor followed by history of previous abortions. Preterm labour was most common ante partum complication and bleeding per vagina comes next to it. Regarding neonatal outcome most of the neonate was normal without complications.

Keywords: Feto-maternal outcome, Placenta previa, Risk factor

\section{INTRODUCTION}

Placenta previa is a condition in which placenta get implanted in the lower uterine segment or cervix, which is a major risk factor for postpartum haemorrhage and morbidity and mortality of the mother and neonate used to increase. Jauniaux et al from London UK has reported based on their systematic review and meta-analysis that the median prevalence of placenta previa was $0.56 \%$ (iqr 0.39 1.24) whereas the median prevalence of placenta previa with pas was $0.07 \%$ (iqr $0.05-0.16) .{ }^{1-3}$ Etiology of placenta previa is unknown and multifactorial. Among various risk factor advancing age of mother, previous surgical procedure involving uterine cavity, Prior miscarriage with operative management, Prior placenta previa and assisted reproductive technology. ${ }^{4,5}$ It is associated with adverse maternal and neonatal outcome.

Placenta previa is associated with neonatal complication like lower APGAR scores, low birth weight, preterm birth, duration of hospitalization increased and increased risk for respiratory distress syndrome. It is also associated with 
maternal complication like postpartum haemorrhage, septicaemia, and hysterectomy and maternal death. ${ }^{6,7}$

After going through literature search we have observed that there are multiple view regarding outcome and risk factor of placenta previa. Sheiner et al has concluded that although an abnormal implantation per se was not an independent risk factor for perinatal mortality, placenta previa should be considered as a marker for possible obstetric complications. Hence, the detection of placenta previa should encourage a careful evaluation with timely delivery in order to reduce the associated maternal and perinatal complications. ${ }^{8}$ Feng et al has concluded that Maternal age $\geq 35$ years and prior uterine operation $\geq 3$ increase the risk of complete previa in mid-pregnancy. ${ }^{9}$ Daskalakis et al has concluded that A history of multiple cesarean deliveries increased the risk for obstetric hysterectomy in women with PP. The type of PP had no effect on maternal and neonatal outcome, with exception of the fact that neonates in the incomplete PP group had lower Apgar scores than neonates in the complete PP group. ${ }^{10}$

Based on the literature survey we have designed with an objective to study the risk factors for placenta previa and feto- maternal outcome in cases of placenta previa.

\section{METHODS}

A retrospective observational study was conducted in the Department of Obstetrics and Gynaecology, Konaseema Institute of Medical Science, Amalapuram, Andhra Pradesh, India conducted from December 2017 to December 2020.

The study was approved by the Institutional Ethics Committee of Konaseema Institute of Medical Science, Amalapuram. As the study involved the retrospective evaluation of existing data obtained from the patient case sheet informed consent of the study participants was not obtained with the approval of IEC. All patients diagnosed to placenta previa and admitted in the department of obstetrics were enrolled for this study based on following selection criteria.

\section{Inclusion criteria}

Pregnant women with history of painless bleeding per vagina after 28 weeks of gestation, ultrasonographically confirmed cases of placenta previa were selected as inclusion criteria.

\section{Exclusion criteria}

Multiple pregnancies, Abruptio placenta, bleeding below 28 weeks of gestation were excluded from the study.

Based on selection criteria 100 singleton deliveries with placenta previa that took place in the department of obstetrics from December 2017 to December 2020 were enrolled and there medical records were considered for analysis.

\section{Method}

From medical record details of patients like age, duration of gestation, parity, clinical presentation, details of current and previous pregnancy, history of warning bleeding and gestational age of diagnosis of placenta previa. Maternal outcome parameters in terms of age of gestation at time of delivery, duration of hospital stay, history of blood transfusion, mode of delivery, need of surgical procedure, postpartum hysterectomy and intensive care treatment. Neonatal outcome was recorded in the form of preterm, meconium aspiration; still born and intrauterine death was recorded.

\section{Statistical analysis}

Data were recorded in excel sheet and statistical Analysis was done with software SPSS-14 version. Data were calculated as percentage and proportions.

\section{RESULTS}

During our study period of three years 100 patients singleton deliveries with placenta previa that took place in the department of obstetrics were enrolled and there medical records were analysed.

Table 1: Demography and obstetric profile of patients.

\begin{tabular}{|c|c|c|c|}
\hline Variable & & Number & Percentage \\
\hline \multirow[t]{2}{*}{ Age (years) } & Below 25 & 15 & 15 \\
\hline & 26 to 30 & 45 & 45 \\
\hline \multirow{2}{*}{$\begin{array}{l}\text { Mean age } \\
28.65 \pm 5.24 \\
\text { years }\end{array}$} & 31 to 35 & 22 & 22 \\
\hline & More than 35 & 18 & 18 \\
\hline \multirow{2}{*}{ Parity } & Nulli & 24 & 24 \\
\hline & Multi & 76 & 76 \\
\hline \multirow{3}{*}{$\begin{array}{l}\text { Age of } \\
\text { gestation }\end{array}$} & 28 to 32 & 14 & 14 \\
\hline & 32 to 36 & 34 & 34 \\
\hline & More than 36 & 52 & 52 \\
\hline \multirow{4}{*}{$\begin{array}{l}\text { Type of } \\
\text { placenta } \\
\text { previa }\end{array}$} & I & 12 & 12 \\
\hline & II & 41 & 41 \\
\hline & III & 38 & 38 \\
\hline & IV & 9 & 9 \\
\hline \multirow{2}{*}{$\begin{array}{l}\text { Degree of } \\
\text { placenta } \\
\text { previa }\end{array}$} & Minor & 38 & 38 \\
\hline & major & 62 & 62 \\
\hline
\end{tabular}

As per Table 1, Mean age 28.65 \pm 5.24 years and most of the patients were between 26 to 30 years of age ( $45 \%$ ), which followed by 31 to 35 years that was $22 \%$, number of patients above 35 years were $18 \%$ and below 20 years were $15 \%$. Regarding parity of patients, $76 \%$ patients were multi and remaining were primi. Age of gestation was between 28 to 32 weeks in 14 patients, 32 to 36 weeks in $34 \%$ patients and more than 36 weeks in $53 \%$ 
patients. Regarding type of placenta previa type I was present in $12 \%$ patients type II was present in $41 \%$ patients type III was present in $38 \%$ patients and type IV was present in $9 \%$ patients. The major degree of placenta previa was common and present in $62 \%$ patients and remaining was minor degree.

Table 2: Distribution of clinical presentation of patients.

\begin{tabular}{|lll|}
\hline Variable & Number & Percentage \\
\hline Pain abdomen & 40 & 40 \\
\hline Bleeding per vagina & 56 & 56 \\
\hline $\begin{array}{l}\text { Pain abdomen and PV } \\
\text { bleeding }\end{array}$ & 32 & 32 \\
\hline Absent fetal movements & 6 & 6 \\
\hline shock & 3 & 3 \\
\hline Asymptomatic & 14 & 14 \\
\hline
\end{tabular}

As per Table 2 regarding distribution of clinical presentation pain abdomen were present in $40 \%$ patients, bleeding per vagina was present in $56 \%$ patients, Pain abdomen and bleeding per vagina was present in $32 \%$ patients, absent fetal movement was present in $6 \%$ patients, shock was present in $3 \%$ patients and $14 \%$ patients were asymptomatic.

Table 3: Distribution of risk factor for placenta previa.

\begin{tabular}{|lll|}
\hline Variable & Number & Percentage \\
\hline Previous H/O LSCS & 48 & 48 \\
\hline Previous abortions & 22 & 22 \\
\hline $\begin{array}{l}\text { previous surgical } \\
\text { procedure involving } \\
\text { uterine cavity }\end{array}$ & 6 & 6 \\
\hline Twin pregnancy & 2 & 2 \\
\hline Anomaly of placenta & 4 & 4 \\
\hline None & 28 & 28 \\
\hline
\end{tabular}

Regarding risk factor for placenta previa $48 \%$ patients have history of previous LSCS, $22 \%$ patients have history of previous abortions, $6 \%$ patients have history of previous surgical procedure involving uterine cavity, $2 \%$ patients presented with twin pregnancy, $4 \%$ patients have anomaly of placenta and $28 \%$ patients have no risk factor.

Regarding anti partum complication bleeding PV was present in $24 \%$ patients, pre term labour was present in $46 \%$ patients, $\mathrm{PIH}$ was present in $10 \%$ patients, abnormal presentation was present in $14 \%$ patients, IUD was present in $2 \%$ patients and shock was detected in $4 \%$ patients. Regarding post-partum complication PPH was present in $18 \%$ patients, placental adherence in $3 \%$ patients and 2 patients developed shock.

Regarding neonatal outcome $89 \%$ were normal without complications, $6 \%$ neonate were preterm, 2 neonate have IUD, Meconium aspiration syndrome was present in 2 patients and 1 neonate was still born.
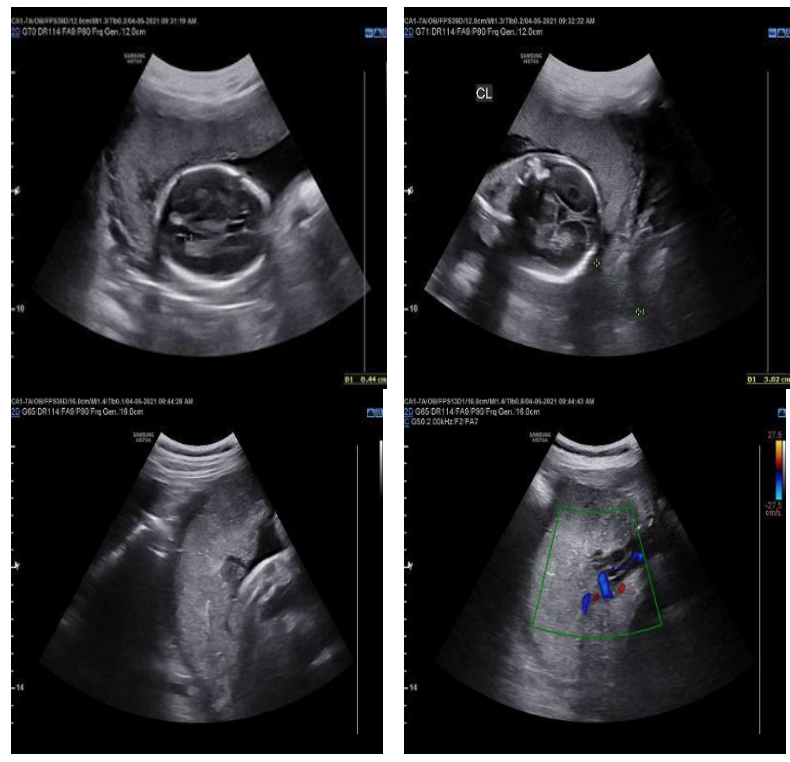

Figure 1: Ultrasonography of placenta previa (various grades).

Table 4: Anti partum and post-partum complications.

\begin{tabular}{|c|c|c|c|}
\hline Variable & & Number & Percentage \\
\hline \multirow{6}{*}{$\begin{array}{l}\text { Anti-partum } \\
\text { complications }\end{array}$} & $\begin{array}{l}\text { Bleeding } \\
\text { PV }\end{array}$ & 24 & 24 \\
\hline & $\begin{array}{l}\text { Pre term } \\
\text { labour }\end{array}$ & 46 & 46 \\
\hline & $\mathrm{PIH}$ & 10 & 10 \\
\hline & $\begin{array}{l}\text { Abnormal } \\
\text { presentation }\end{array}$ & 14 & 14 \\
\hline & IUD & 2 & 2 \\
\hline & Shock & 4 & 4 \\
\hline \multirow{5}{*}{$\begin{array}{l}\text { Post-partum } \\
\text { complications }\end{array}$} & PPH & 18 & 78.26 \\
\hline & $\begin{array}{l}\text { Placental } \\
\text { adherence }\end{array}$ & 3 & 13.04 \\
\hline & $\begin{array}{l}\text { Injury to } \\
\text { bowel and } \\
\text { bladder }\end{array}$ & 0 & 0 \\
\hline & shock & 2 & 8.69 \\
\hline & $\begin{array}{l}\text { Maternal } \\
\text { mortality }\end{array}$ & 0 & 0 \\
\hline
\end{tabular}

Table 5: Neonatal outcome in placenta previa.

\begin{tabular}{|lll|}
\hline Variable & Number & Percentage \\
\hline Normal & 89 & 89 \\
\hline Preterm & 6 & 6 \\
\hline IUD & 2 & 2 \\
\hline $\begin{array}{l}\text { Meconium aspiration } \\
\text { syndrome }\end{array}$ & 2 & 2 \\
\hline Still born & 1 & 1 \\
\hline
\end{tabular}

\section{DISCUSSION}

In present study we have analysed 100 patients with placenta previa for risk factor and feto maternal outcome. 
In present study mean age $28.65 \pm 5.24$ years and most of the patients were between 26 to 30 years of age. Elizabeth et al has reported that women with placenta previa had a significantly higher mean age $(29.07, \mathrm{SD}=6.12$ (years)) than their unaffected counterparts $(27.47, \mathrm{SD}=6.05$ (years)), this finding support our study but most common age were below 20 years which doesn't support our study. ${ }^{11}$ Hossain et al has concluded that incidence of placenta previa is common in third decade and increases with parity which support our study. ${ }^{12}$ Most common gestational age for diagnosis was 36 weeks this finding is supported by study of Dashe et al. ${ }^{13}$ Regarding type and degree of placenta previa type II and III are common and major degree are common than minor. This finding is supported by the work of Wasan et al. ${ }^{14,15}$

In our study regarding clinical presentation, pain abdomen were present in $40 \%$ patients, bleeding per vagina was present in $56 \%$ patients, Pain abdomen and bleeding per vagina was present in $32 \%$ patients and $14 \%$ patients were asymptomatic which corroborates with the study of Ikechebelu et al. ${ }^{16}$

In present study previous LCSC is common risk factor followed by history of previous abortions. Kiondo et al has reported that patients who had previous delivery by caesarean section were associated with an increased risk of placenta praevia. Ananth et al has reported that there is a strong association between having a previous cesarean delivery, spontaneous or induced abortion, and the subsequent development of placenta previa. These two study finding support our study. ${ }^{17,18}$

Preterm labour was most common ante partum complication and bleeding per vagina comes next to it. Shock and IUD are present in $2 \%$ and $4 \%$ patients' respectively. PPH was most common post-partum complication. This finding is supported by the work of Adere et al. ${ }^{19}$

Regarding neonatal outcome most of the neonate were normal without complications, $6 \%$ neonate were preterm, 2 neonate have IUD, Meconium aspiration syndrome was present in 2 patients and 1 neonate was still born. This finding is supported by the work of Crane et al. ${ }^{20}$

\section{CONCLUSION}

From our study we can conclude that placenta previa is common in multiparous women in third decade of life and commonly detected at 36 weeks. Major degree of placenta previa is most common. Bleeding per vagina was most common clinical presentation and LCSC is common risk factor followed by history of previous abortions. Preterm labour was most common ante partum complication and bleeding per vagina comes next to it. Regarding neonatal outcome most of the neonate was normal without complications.
Funding: No funding sources

Conflict of interest: None declared

Ethical approval: The study was approved by the Institutional Ethics Committee

\section{REFERENCES}

1. Ellenson LH, Pirog EC. The female genital tract Robbins and cotran, pathologic basic of disease. $8^{\text {th }}$ Edition. Elsevier publication. 2010:22,1055.

2. Bagga FM, Sze A. Placenta Previa. In: Stat Pearls Treasure Island (FL): Stat Pearls Publishing; 2021 Jan-. Available at https:// www. ncbi. nlm. nih. gov/books/NBK539818/. Accessed on 12 April 2020.

3. Jauniaux E, Grønbeck L, Bunce C, Roos LJ, Collins SL. Epidemiology of placenta previa accreta: a systematic review and meta-analysis. BMJ Open. 2019;9(11):e031193.

4. Kollmann M, Gaulhofer J, Lang U, Klaritsch P. Placenta praevia: incidence, risk factors and outcome. J Matern Fetal Neonatal Med. 2016;29(9):1395-8.

5. Jing L, Wei G, Mengfan S, Yanyan H. Effect of site of placentation on pregnancy outcomes in patients with placenta previa. PLoS One. 2018;13(7):e0200252.

6. Ahn KH, Lee EH, Cho GJ, Hong SC, Oh MJ, Kim HJ. Anterior placenta previa in the mid-trimester of pregnancy as a risk factor for neonatal respiratory distress syndrome. PLoS One. 2018;13(11):e0207061.

7. Silver RM. Abnormal placentation: placenta previa, vasa previa, and placenta accreta. Obstet Gynecol. 2015;126(3):654-68.

8. Sheiner E, Vardi I, Hallak M, Hershkowitz R, Katz M, Mazor M. Placenta previa: obstetric risk factors and pregnancy outcome. J Matern Fetal Med. 2001;10(6):414-9.

9. Feng Y, Li XY, Xiao J, Li W, Liu J, Zeng X, et al. Risk factors and pregnancy outcomes: complete versus incomplete placenta previa in mid-pregnancy. Curr Med Sci. 2018;38(4):597-601.

10. Daskalakis G, Simou M, Zacharakis D, Detorakis S, Akrivos N, Papantoniou N, et al. Impact of placenta previa on obstetric outcome. Int J Gynaecol Obstet. 2011;114(3):238-41.

11. Senkoro EE, Mwanamsangu AH, Chuwa FS, Msuya SE, Mnali OP, Brown BG, et al. Frequency, risk factors, and adverse fetomaternal outcomes of placenta previa in Northern Tanzania. J Pregnancy. 2017;2017:5936309.

12. Hossain GA, Islam SM, Mahmood S, Chakraborty RK, Akhter N, Sultana S. Placenta previa and it's relation with maternal age, gravidity and cesarean section. Mymensingh Med J. 2004;13(2):143-8.

13. Dashe JS, McIntire DD, Ramus RM, Ramos R, Twickler DM. Persistence of placenta previa according to gestational age at ultrasound detection. Obstet Gynecol. 2002;99(51):692-7. 
14. Salman WH, Waeely FA. Predisposing factors and pregnancy outcome in different types of placenta previa. Int J Adv Res Biol Sci. 2009;6(2):13-23.

15. Sekiguchi A, Nakai A, Kawabata I, Hayashi M, Takeshita T. Type and location of placenta previa affect preterm delivery risk related to antepartum hemorrhage. Int J Med Sci. 2013;10(12):1683-8.

16. Ikechebelu JI, Onwusulu DN. Placenta praevia: review of clinical presentation and management in a Nigerian teaching hospital. Niger $J$ Med. 2007;16(1):61-4.

17. Kiondo P, Wandabwa J, Doyle P. Risk factors for placenta praevia presenting with severe vaginal bleeding in Mulago hospital, Kampala, Uganda. Afr Health Sci. 2008;8(1):44-9.
18. Ananth CV, Smulian JC, Vintzileos AM. The association of placenta previa with history of cesarean delivery and abortion: a metaanalysis. Am J Obstet Gynecol. 1997;177(5):1071-8.

19. Adere A, Mulu A, Temesgen F. Neonatal and maternal complications of placenta praevia and its risk factors in tikur anbessa specialized and gandhi memorial hospitals: unmatched case-control study. J Pregnancy. 2020;2020:5630296.

20. Crane JM, Den HMC, Dodds L, Armson BA, Liston R. Neonatal outcomes with placenta previa. Obstet Gynecology. 1999;93(4):541-4.

Cite this article as: Kothapalli D, Kolluru K.

Placenta previa and its effect on maternal and fetal outcome; retrospective observational study. Int $\mathrm{J}$ Reprod Contracept Obstet Gynecol 2021;10: 2720-4. 